\title{
Helmut Böttiger, Die Gruppe 47
}

\section{Ruth Vogel-Klein}

\section{OpenEdition \\ Journals}

Édition électronique

URL : http://journals.openedition.org/ifha/8967

DOI : 10.4000/ifha. 8967

ISSN : 2198-8943

Éditeur

IFRA - Institut franco-allemand (sciences historiques et sociales)

\section{Référence électronique}

Ruth Vogel-Klein, « Helmut Böttiger, Die Gruppe 47 », Revue de l'IFHA [En ligne], Date de recension, mis en ligne le 13 décembre 2017, consulté le 24 septembre 2020. URL : http://journals.openedition.org/ ifha/8967 ; DOl : https://doi.org/10.4000/ifha.8967

Ce document a été généré automatiquement le 24 septembre 2020.

(CIFHA 


\section{Helmut Böttiger, Die Gruppe 47}

Ruth Vogel-Klein

\section{RÉFÉRENCE}

Helmut Böttiger, Die Gruppe 47. Als die deutsche Literatur Geschichte schrieb, München: DVA, 2012, 478 p., $15 €$ 
De 1947 à 1967, l'écrivain et découvreur de talents Hans Werner Richter a réuni chaque année sous le nom de Groupe 47 des écrivains et des poètes souvent peu connus, qui ont constitué par la suite des grands noms de la littérature de langue allemande: Ilse Aichinger, Ingeborg Bachmann, Paul Celan, Günter Eich, Günter Grass, Hans Magnus Enzensberger, Heinrich Böll, Peter Handke, Martin Walser, entre autres. Ce volume prend en compte les nombreuses analyses et études parues précédemment sur le Groupe 47, notamment les excellents ouvrages de Stephan Braese (1999) et de Heinz L. Arnold (2004), et procède à un examen détaillé des sources disponibles, dont la correspondance de H. W. Richter (1997) et les archives radiophoniques. Les 21 chapitres résument de façon

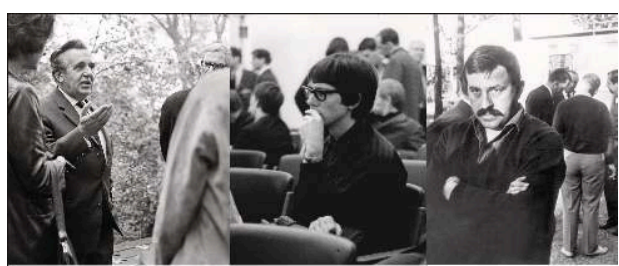

HELMUT BÖTTIGER

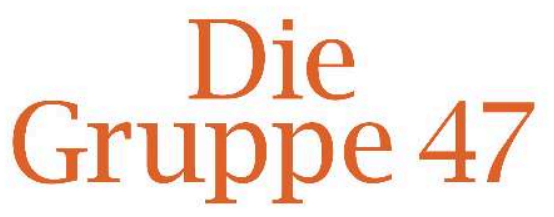

Als die deutsche Literatur Geschichte schrieb

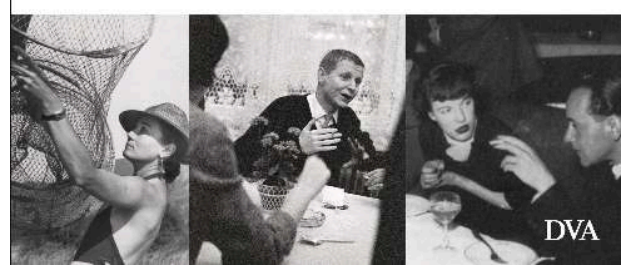
chronologique les réunions du groupe jusqu'en 1967 et présentent de façon détaillée le parcours des écrivains ou des critiques majeurs. H. Böttiger souligne la grande fluctuation des participants - d'où la difficulté à délimiter le Groupe 47, qui a compté plus d'une centaine de personnes.

En introduction, il évoque le décalage du groupe initial par rapport aux contextes culturels et littéraires des années 50 et 60 , dominés par les positions antidémocratiques, élitistes et opportunistes des intellectuels et écrivains influents. Il rappelle que $\mathrm{H}$. W. Richter, ancien opposant au nazisme et partisan d'un socialisme démocratique, plus tard militant du mouvement anti-nucléaire, a aussi bien écarté les écrivains militaristes et d'extrême droite que les représentants d'une "calligraphie » littéraire. Cependant, on lit que Richter et la plupart des écrivains de la première génération, soudés par des parcours biographiques communs (le nazisme, la vie militaire), ont manifesté des réticences à l'égard d'écrivains juifs et émigrants. H. Böttiger revient longuement sur l'accueil plus qu'hostile réservé à Paul Celan en 1952, qui s'est même vu insulté, et évoque la réception très favorable dont a au contraire bénéficié l'écrivaine et poétesse juive autrichienne Ilse Aichinger, dont les textes présentés ne semblaient pas se référer au génocide. L'auteur remarque que dans les textes très divers des jeunes Allemands du Groupe 47, à l'exception de Böll, le sentiment de culpabilité par rapport au nazisme était inexistant et la représentation de la Shoah et des crimes de guerre allemands quasi absente : "Le sentiment partagé de vouloir tirer un trait sur le passé a créé un lien puissant. » (p. 75).

Dans l'ensemble, les écrivains invités, souvent relativement jeunes et peu connus au départ, n'avaient pas de canon esthétique commun, et l'auteur déplore que H. Richter, campant sur des positions "bornées", ait exclu dans un premier temps certains tenants d'un renouveau esthétique, avant de revenir ensuite sur cette décision. Le jugement littéraire du groupe se manifestait dans l'attribution consensuelle du Prix du Groupe 47, dont Böll, Aichinger, Eich, Bachmann, Grass et Bobrowski ont été les 
lauréats, entre autres. Des étapes marquantes sont évoquées, comme la percée fulgurante de la poétesse « fétiche » Ingeborg Bachmann en 1953 et la réunion de 1958, où Grass présenta Le Tambour dans un enthousiasme général. Les attaques violentes d'hommes politiques de droite contre le Groupe 47 en 1963 sont analysées comme le signe de la notoriété du groupe et de son impact sur l'opinion politique. Un long portrait est consacré à H. M. Enzensberger, figure marquante au carrefour de la littérature, des médias et du journalisme, que l'auteur ne considère pas comme un écrivain de talent, mais plutôt comme l'habile promoteur de son propre succès auprès des médias.

Dans la rétrospective, $\mathrm{H}$. Böttiger fait état de la transformation progressive des réunions annuelles de lectures d'auteurs, commentées et critiquées par leurs pairs, en tribune médiatique de plus en plus influente, comme en témoigne la présence de plus en plus dominante de critiques littéraires, d'éditeurs et de journalistes. Il retrace les réseaux d'influence autour du groupe et étudie notamment le rôle des écrivains Andersch et Höllerer, acteurs culturels d'avant-garde dans le domaine de l'édition, de l'université et de la radio, qui ont ouvert la voie à la publication, à la présentation et à la diffusion des œuvres du groupe. De nombreuses pages sont consacrées au rôle politique du Groupe 47 et de ses membres, foncièrement opposés à la CDU et aux intellectuels de droite. Les liens de quelques membres avec le SPD sont analysés en détail. Précédée et accompagnée par les contestations estudiantines et des polémiques lancées par de jeunes auteurs comme Peter Handke, la fin du groupe en 1967 apparaît comme une issue inévitable.

Ce volume, bien écrit et documenté, éclaire de façon excellente l'histoire culturelle ouest-allemande.

\section{INDEX}

Thèmes : Histoire de la culture

\section{AUTEURS}

\section{RUTH VOGEL-KLEIN}

École Normale Supérieure, Paris 